\section{A Route for Intravenous Injection in the Albino Rat}

Drs. Everett and Sawyer ${ }^{1}$ claim to have found that the small saphenous vein on the foot of the rat is far more satisfactory than the more commonly used tail vein for intravenous injection.

We, in this laboratory, found even this vessel in the albino rat $(200 \mathrm{gm}$.) to be too small and difficult to use, and have developed the following site and technique to our greater satisfaction; this, also, is on the unanresthetized rat.

The rat is placed quickly and comfortably into the animal restrainer ${ }^{2}$, leaving one hind-limb free (3040 sec.). The long hairs are then removed from ankle to hip on the posterior surface of the free limb, using electric clippers (10-15 sec.), then wet-shaved (about 30 sec.) to expose the quite large superficial vein-the lateral marginal vein ${ }^{3}$.

The rat can be held firmly by an assistant placing the right hand over the hips of the animal, with the free limb passing between the first and second fingers and applying sufficient pressure to cause this vein to become quite prominent without the use of any form of tourniquet. The assistant's left hand holds the foot firmly.

A 27-gauge, $\frac{1}{2}$-in. hypodermic needle is suitable for this vein, though some operators may prefer a 26 -gauge.

Medical Division,

\section{Kenneth A. Pearce}

Chemical Defence Experimental Establishment, Porton Down, Salisbury, Wilts. May 14.

${ }^{1}$ Sawyer, C. H., and Everett, J. W., Nature, 178, 268 (1956).

${ }^{2}$ Pearce, K. A., Proc. J. Physiol., 135, No. 2 (1957).

${ }^{3}$ Greene, E. C., "The Anatomy of the Rat".

\section{Intracellular Recording from Spinal Motoneurones following Stimulation of Medullary Pyramids}

ALthough a rich literature is available concerning the anatomy and the physiology of the lateral corticospinal tract, no reports have been published in which intracellular electrodes were employed in studying the synaptic connexions of the corticospinal tract in the lumbar spinal cord. Lloyd ${ }^{1}$ used extracellular and ventral root recording, and laid the theoretical groundwork for the present study.

I have now shown that motoneurones are excited by corticospinal impulses in the same manner as that in which they are excited by afferent (orthodromic), antidromic or direct routes of stimulation ${ }^{2-7}$.

Glass micropipettes filled with potassium chloride were inserted into cat spinal interneurones and motoneurones, identified according to criteria established by Eccles ${ }^{3}$ and Frank and Fuortes. The potentials led off from these cells were amplified and recorded using the technique of Frank and Fuortes ${ }^{4}$ in one case and that of $\mathrm{Li}$ and $\mathrm{Jasper}^{8}$ in all the other experiments. Stimulation of medullary pyramids was accomplished by direct insertion of electrodes (platinum or steel, insulated to tip) following ventral neck dissection. All animals were decerebrate. Contralateral limb movement was used for identifying the position of the stimulating pair with respect to the decussation of the pyramids.

The pyramidal tract stimulus (isolated by radiofrequency) consisted in a train of seven to ten square pulses of amplitude 7.5-10.0 V., duration 0.1 msec., at 1.0 msec. intervals. Such trains summated with potentials recorded from a motor neurone in response to dorsal root stimulation, or antidromic stimuli of insufficient intensity to invade the soma, to produce firing of motoneurones. Non-invading spikes following maximal ventral root stimulation were helped to invade the soma by pyramidal stimulation. Small responses to the second of two antidromic shocks within critical stimulus interval ${ }^{4}$ were also helped to invade by the pyramidal stimulus. Pyramidal stimulation alone produced graded subthreshold depolarization resembling dorsal root synaptic potential, although shorter in duration. Progressive increase in the strength and/or frequency of such stimulation resulted in the firing of motoneurones. The latency, amplitude and duration of the responses were similar to those obtained by other means. All responses exhibited inflexions in the rising phase of the spike, a finding which presupposes the mode of excitation of the motoneurone by corticospinal impulses to be the same as that found for other routes by other authors ${ }^{2,7,9}$.

Thus far in the study, eight interneurones have been penetrated, and the activity of five of them following physiological stimulation (toe-pad pinch) was increased by pyramidal stimulation, while three were inhibited. The patterns of response of the interneurones fell roughly into two groups which will be described elsewhere at length. The implications of these results with respect to corticospinal control of movement will also be discussed elsewhere.

Thanks are due to Drs. Karl Frank, Choh-luh Li, Cosimo Ajmone-Marsan, and Messrs. Saxton Howard and Samuel Cooper for their help in various phases of this investigation.

Roger Merritt Morrell

61 Townsend Avenue,

Staten Island 4, N.Y. May 1.

${ }^{1}$ Lloyd, D. P. C., J. Neurophysiol., 4, 525 (1941).

"Araki, T., and Otani, T., J. Neurophysiol., 18, 472 (1955).

${ }^{3}$ Brock, L. G., Coombs, J. S., and Eccles, J. C., J. Physiol., 117, 431 (1952).

4 Frank, K., and Fuortes, M. G. F., J. Physiol., 130, 625 (1955).

${ }^{5}$ Brock, L. G., Coombs, J. S., and Eccles, J. C., J. Physiol., 122, 429 (1953).

' Coombs, J. S., Eccles, J. C., and Fatt, P., J. Physiol., 130, 374 (1955). Trank, K., and Fuortes, M. G. F., J. Physiol., 134, 451 (1956).

${ }^{8}$ Li, C. L., and Jasper, H., J. Physiol., 121, 117 (1953).

- Fatt, P., J. Neurophysiology, V 20, No. 1 (1957).

\section{Differentiation of Somatic and Autonomic Nerve Fibres in Tissue Sections}

VARIOUS morphological types of encapsulated and non-encapsulated nerve endings in glabrous skin and mucous membranes have been described by several workers ${ }^{1,2}$, and these findings have been confirmed recently in a study of the innervation of selected regions of the oral mucosa in a number of mammals ${ }^{\mathbf{s}}$. In contrast, little attention has been given in the past to the nature of the nerve plexuses from which these terminations arise, and the investigation has been extended to include this aspect of the problem 4 .

Although the topographical features of the plexuses cain be demonstrated satisfactorily using routine neurohistological methods, such as methylene blue 